\title{
No gynecologist in town: the gynecological care of women in rural Taiwan
}

\author{
This article was published in the following Dove Press journal: \\ Patient Preference and Adherence \\ 29 July 2015 \\ Number of times this article has been viewed
}

\author{
Li-Jung Lai' \\ Chia-Lin Chou ${ }^{2}$ \\ $\mathrm{H}$ Irene $\mathrm{Su}^{3}$ \\ Tzeng-Ji Chen ${ }^{1,4}$ \\ Li-Fang Chou ${ }^{5}$ \\ Yueh-Ching $\mathrm{Chou}^{2,6,7}$ \\ Shinn-Jang Hwang ${ }^{1,8}$ \\ Hann-Chin $\mathrm{Yu}^{9,10}$ \\ 'Department of Family Medicine, \\ ${ }^{2}$ Department of Pharmacy, Taipei \\ Veterans General Hospital, Taipei, \\ Taiwan; ${ }^{3}$ Department of Reproductive \\ Medicine, University of California, San \\ Diego, CA, USA; ${ }^{4}$ Institute of Hospital \\ and Health Care Administration, \\ School of Medicine, National Yang- \\ Ming University, ${ }^{5}$ Department of \\ Public Finance, National Chengchi \\ University, ${ }^{6}$ Department and \\ Institute of Pharmacology, National \\ Yang-Ming University, ${ }^{7}$ College of \\ Pharmacy, Taipei Medical University, \\ ${ }^{8}$ Department of Family Medicine, \\ School of Medicine, National Yang- \\ Ming University, Taipei, Taiwan; \\ ${ }^{9}$ Taipei Veterans General Hospital \\ Hsinchu Branch, Hsinchu County, \\ Taiwan; ${ }^{10}$ Department of Healthcare \\ Management, Yuanpei University, \\ Hsinchu, Taiwan
}

\begin{abstract}
Background: A shortage of gynecologists exists in many countries. Even within an affluent country, gynecological clinics might not be evenly distributed. The purpose of the study was to investigate the disparity in gynecological care between adult women living in towns with and without gynecologists in Taiwan.

Methods: Data sources were the cohort datasets of the National Health Insurance Research Database, with claims data of 1 million beneficiaries in 2010. A woman's residency was operationally inferred from the locations where she had most frequently visited physicians' clinics or local community hospitals within the year.
\end{abstract}

Results: In Taiwan, 145 (39.4\%) of 368 towns had no practicing gynecologist. Of 382,167 women with health care use in the datasets, 21,794 (5.7\%) lived in towns without a gynecologist. The overwhelming majority of these towns lay in sparsely populated, rural areas. During the year, 132,702 women (34.7\%) had sought medical help for gynecological diseases and $113,698(29.8 \%)$ had visited gynecologists for gynecological diseases. Women in towns without a gynecologist were less likely to consult for gynecological diseases $(23.8 \%$ versus $35.4 \%$; $P<0.001)$ and visit gynecologists $(18.7 \%$ versus $30.4 \% ; P<0.001)$ than women in towns with a gynecologist. The disparity existed in each age group. Among 5,189 adult women living in towns without a gynecologist and having gynecological diseases, $78.5 \%$ (number $[n]=4,074$ ) visited gynecologists out of town, especially for infertility, benign disorders of the uterus and ovaries, gynecological examinations, and contraceptive problems, and by contrast $23.3 \%(n=1,209)$ visited nongynecologists in town, most commonly for menopausal disorders, endometriosis and pelvic pain, menstrual disorders and hormonal dysfunction, and genital dysplasia.

Conclusion: Gynecological care of rural women was adversely affected by the shortage of gynecologists. The consequences of accessibility in underserved areas deserve further investigation.

Keywords: gynecological care, urban-rural health service, women's health

\section{Introduction}

A shortage of gynecologists exists worldwide, not only in developing countries, ${ }^{1}$ but also in developed countries such as Japan, ${ }^{2}$ Canada, ${ }^{3}$ and the United States. ${ }^{4}$ In a report of a national birthing initiative for Canada in 2008, the Society of Obstetricians and Gynaecologists for Canada reported that the human resources in obstetrics and gynecology care are markedly decreasing. There were 1,650 gynecologists and 36\% of them planned to retire. ${ }^{3}$ In the US, they also face a workforce shortage of obstetricians and gynecologists due to the Balanced Budget Act of 1997 and the continuous growth of the population; the estimated shortage of the workforce will reach at least $40 \%$ by $2030 .{ }^{4}$ Most studies on this issue have analyzed factors related to the supply of gynecologists: prolonged working hours; insufficient reimbursements; malpractice
Correspondence: Hann-Chin Yu Taipei Veterans General Hospital Hsinchu Branch, No 8I, Sec I, Zhongfeng Road, Zhudong Township, Hsinchu County 310, Taiwan

Tel +886 35961186

Fax +88635969591

Email handsomeyhc20I@yahoo.com.tw 
risks; and so forth. ${ }^{5-7}$ However, the impact of limited access to gynecologists has not been well documented.

In Taiwan, an island country with a population of 23 million, a national health insurance system, and a gross domestic product per capita of US $\$ 18,588$ in $2010,{ }^{8}$ over $50 \%$ of 368 towns had no practicing gynecologist. ${ }^{9}$ We conducted a nationwide, population-based study to investigate the gynecological care of women in Taiwan. The aim of our study was to determine whether women living in towns without gynecologists would have fewer gynecological visits than women living in areas with ready access to gynecologists. In addition, in towns without a gynecologist, we further analyzed the help-seeking behaviors of women, such as seeking health care by nongynecologists or from other towns.

\section{Methods}

\section{Data sources}

National Health Insurance (NHI) in Taiwan started in 1995 and provides comprehensive health care coverage for more than $99 \%$ of its inhabitants. The Bureau of NHI has generated deidentified research claims datasets. ${ }^{10}$ In the current study, we obtained a cohort dataset (Longitudinal Health Insurance Database 2010) with claims data on 1 million people randomly sampled from all NHI beneficiaries in 2010 . There were 15,431,528 records of ambulatory visits in 2010 . Ambulatory records included patient identification numbers, sex, birth date, date of consultation, medical facility, specialty of consulted physician, and three fields of diagnoses coded according to the International Classification of Diseases, Ninth Revision, Clinical Modification (ICD-9-CM). ${ }^{11}$ The towns in which medical facilities were located were determined by the registry for contracted medical facilities (HOSB2010.DAT). The basic data of 368 townships were available from the Directorate-General of Budget, Accounting and Statistics of the government. ${ }^{8}$

\section{Study design}

The conduct of this cross-sectional study has been approved by the institutional review board of Taipei Veterans General Hospital, Taipei, Taiwan.

The ambulatory visits of all adult women aged 18 years or older in 2010 were included. First, we divided towns into "towns with gynecologist" and "towns without gynecologist", according to the locations of gynecology clinics or hospitals with outpatient gynecology departments. Because the NHIRD (National Health Insurance Research Database) did not provide the residence data of each beneficiary, we devised an algorithm to infer where a patient lived. Patients were assigned residence to towns where they incurred the most health care visits. If a patient had the same number of visits to more than one town in a year, the town with the earliest visit was assigned. Accordingly, the patients were categorized into women living in towns with a practicing gynecologist and women living in towns without a practicing gynecologist.

Gynecological care was defined as a visit with any of the following 12 diagnosis groups: 1) lower genital tract infections (tuberculosis, herpes, condyloma acuminatum, syphilis, gonorrhea, other venereal diseases, candida, trichomonas) (ICD-9-CM: 016.6-016.7, 054.1, 078.11, 091.0, 098.0-098.3, 099, 112.1, and 131.0); 2) infertility, 628; 3 ) genital dysplasia (precancerous lesions of the vulva, vagina, and cervix) (ICD-9-CM: 622-624); 4) menopausal disorders (ICD-9-CM: 618 and 627); 5) menstrual disorders and hormonal dysfunction (perimenopausal bleeding, dysfunctional uterine bleeding, ovarian hyperestrogenism, ovarian dysfunction, or irregular menstrual cycles) (ICD-9-CM: 256 and 626); 6) endometriosis and pelvic pain (ICD-9-CM: 617 and 625); 7) reproductive tract malignancy (carcinoma in situ and invasive disease of the genital tract) (ICD-9-CM: 179-184 and 233.1-233.3); 8) inflammatory disease of the upper genital tract (disease of the uterus, ovaries, and fallopian tubes including cervicitis, salpingitis, endometritis, and tubo-ovarian abscess) (ICD-9-CM: 614-616); 9) benign disorders of the uterus and ovaries (benign ovarian cysts or tumors, leiomyomas, endometrial polyps, or hyperplasia) (ICD-9-CM: 218-220 and 620-621); 10) other disorders of the female genital organs (ICD-9-CM: 221, 619, and 629); 11) gynecological examination (ICD-9-CM: V72.3 and V76.2); and 12) encounter for contraceptive management (ICD-9-CM: V25). The grouping was adopted from the work of Nicholson et al ${ }^{12}$ with slight modification.

\section{Statistical analysis}

Data extraction and computation were performed with the Perl programming language, version 5.14.2. ${ }^{13}$ SPSS software (version 17) was used for statistical analysis. Pearson's $\chi^{2}$ test was used for group comparisons. A $P$-value $<0.05$ (twotailed) was considered statistically significant. The proportion of women who incurred at least one health care visit with a gynecological diagnosis was determined. Of these, the proportion who obtained care from a gynecologist was determined. Visits with a gynecological diagnosis, as well as visits with care from a gynecologist, were compared by residence status (ie, towns with and without a gynecologist). These analyses were further stratified by age and diagnosis. 
For women living in towns without a gynecologist, we further analyzed the types of clinics where they sought help for gynecological diseases. The clinics were classified into clinics in towns without a gynecologist, nongynecological clinics in towns with a gynecologist, and gynecological clinics in towns with a gynecologist. The analysis was stratified by diagnosis groups to reveal the associations between the type of gynecological diseases and the decision to seek help out of town.

\section{Results}

Within the 1-million person cohort dataset in 2010, there was no practicing gynecologist in 145 (39.4\%) of the 368 towns in Taiwan (Table 1). According to the official statistics, towns without a gynecologist occupied nearly three-fifths of the total area, with approximately $11.0 \%$ of the female population in Taiwan. The cohort datasets included 407,731 adult women, of which 382,167 (93.7\%) had utilized the NHI ambulatory services in 2010, and their residencies could be operationally identified using the algorithm of our study. In this cohort, 5.7\% (number $[n]=21,794$ ) of adult women with NHI use resided in towns without a gynecologist.

Among adult women with NHI use, $34.7 \%(\mathrm{n}=132,702)$ had sought medical help for gynecological diseases and $29.8 \%(n=113,698)$ had visited gynecologists for gynecological diseases. Women living in towns without a gynecologist were less likely to have visits for gynecological diseases than women living in towns with a gynecologist $(23.8 \%$ versus $35.4 \%$, respectively; $P<0.001$ ). Women living in towns without a gynecologist also visited gynecologists less frequently than women living in towns with a gynecologist
( $18.7 \%$ versus $30.4 \%$, respectively; $P<0.001$ ). The disparity persisted within each age group (Table 2).

The distribution of gynecological diseases varied by age; while menstrual disorders and hormonal dysfunction were most common in young women, inflammatory disease of the upper genital tract became the leading disease in the other age groups (Table 3 ). Women in towns without gynecologists were less likely to be diagnosed with one of these diseases except for reproductive tract malignancies and contraceptive management.

Among 5,189 adult women living in towns without a gynecologist and who had visits for gynecological diseases, $23.3 \%(n=1,209)$ had consulted nongynecologists in town and $78.5 \%(n=4,074)$ had consulted gynecologists out of town for gynecological diseases during the year. For all diagnosis groups, women tended to obtain care from gynecologists out of town. Still, a number of patients visited nongynecologists in town, most often for menopausal disorders, endometriosis and pelvic pain, menstrual disorders and hormonal dysfunction, and genital dysplasia (Table 4).

\section{Discussion}

In a densely populated country such as Taiwan, two-fifths of towns still had no practicing gynecologist. This percentage in our study was lower than that published by the Taiwan Medical Association (53\%), ${ }^{9}$ and it raises the question of whether the supply and distribution of gynecologists are deteriorating in Taiwan. An alternate explanation was that we calculated these rates throughout the year, while the official statistics were done at a time point at the end of the year. From our analysis, the number of female inhabitants in a town seemed to play a major role in the location of gynecological clinics.

Table I Distribution of population and area in towns with and without a gynecologist in Taiwan, 2010

\begin{tabular}{|c|c|c|c|}
\hline & Towns with a gynecologist, n (\%) & Towns without a gynecologist, n (\%) & Total, $\mathbf{n}$ \\
\hline Towns, $\mathrm{n}$ & $223(60.6 \%)$ & 145 (39.4\%) & 368 \\
\hline Aggregate area $\left(\mathrm{km}^{2}\right)^{\mathrm{a}}$ & $14,697.5(40.6 \%)$ & $21,493.5(59.4 \%)$ & 36,191 \\
\hline Aggregate population ${ }^{\mathrm{a}}$ & $20,487,534(88.6 \%)$ & 2,636,332 (I I.4\%) & $23,123,866$ \\
\hline \multicolumn{4}{|l|}{ Female population ${ }^{\mathrm{a}}$} \\
\hline Sum & $10,354,907$ (89.0\%) & I,279,674 ( I I.0\%) & II,634,58| \\
\hline Mean (SD) & $46,434.6(50,674.5)$ & $8,825.3(8,139.2)$ & \\
\hline Minimum & 220 & 16 & \\
\hline Maximum & 308,683 & 46,641 & \\
\hline \multicolumn{4}{|c|}{ Adult women in the study } \\
\hline Sum & 360,373 (94.3\%) & $21,794(5.7 \%)$ & 382,167 \\
\hline Mean (SD) & I,6I6.0 (I,949.3) & I50.3 (I 48.0) & \\
\hline Minimum & 4 & 0 & \\
\hline Maximum & 11,189 & 894 & \\
\hline
\end{tabular}

Notes: aCalculated from the basic data of 368 townships published by the Directorate-General of Budget, Accounting and Statistics of the Taiwan government. ${ }^{8}$ Abbreviations: $n$, number; SD, standard deviation. 
Table 2 Gynecologic care access for adult women in 2010 stratified by age group and residency type

\begin{tabular}{|c|c|c|c|}
\hline & $\begin{array}{l}\text { Women living in towns } \\
\text { with a gynecologist, } n \text { (\%) }\end{array}$ & $\begin{array}{l}\text { Women living in towns } \\
\text { without a gynecologist, } n \text { (\%) }\end{array}$ & $P$-value \\
\hline \multicolumn{4}{|l|}{ Total } \\
\hline Total number of women & 360,373 & 21,794 & \\
\hline Visit for gynecological disease & $127,5 \mid 3(35.4 \%)$ & $5,189(23.8 \%)$ & $<0.001$ \\
\hline Visits for gynecologic disease with a gynecologist & $109,624(30.4 \%)$ & $4,074(18.7 \%)$ & $<0.001$ \\
\hline \multicolumn{4}{|l|}{ 18-29 years } \\
\hline Total number of women & 86,529 & 2,962 & \\
\hline Visit for gynecological disease & $37,126(42.9 \%)$ & $1,027(34.7 \%)$ & $<0.001$ \\
\hline Visits for gynecologic disease with a gynecologist & $31,152(36.9 \%)$ & $820(27.7 \%)$ & $<0.001$ \\
\hline \multicolumn{4}{|l|}{$30-44$ years } \\
\hline Total number of women & || $2,83 \mid$ & 4,993 & \\
\hline With gynecological disease & $50,509(44.8 \%)$ & $1,770(35.4 \%)$ & $<0.001$ \\
\hline With visits to a gynecologist & $44,453(39.4 \%)$ & I,497 (30.0\%) & $<0.001$ \\
\hline \multicolumn{4}{|l|}{$45-64$ years } \\
\hline Total number of women & 114,157 & 7,913 & \\
\hline Visit for gynecological disease & $34,969(30.6 \%)$ & $1,936(24.5 \%)$ & $<0.001$ \\
\hline Visits for gynecologic disease with a gynecologist & $30,076(26.3 \%)$ & $1,466(18.5 \%)$ & $<0.001$ \\
\hline \multicolumn{4}{|l|}{$\geq 65$ years } \\
\hline Total number of women & 46,856 & 5,926 & \\
\hline Visit for gynecological disease & 4,909 (10.5\%) & $456(7.7 \%)$ & $<0.001$ \\
\hline Visits for gynecologic disease with a gynecologist & $3,943(8.4 \%)$ & 291 (4.9\%) & $<0.001$ \\
\hline
\end{tabular}

Note: aPearson's $\chi^{2}$ test.

Abbreviation: $\mathrm{n}$, number.

Previous literature had also found that a threshold population level was necessary to support a medical provider, especially a specialist, ${ }^{14,15}$ and gynecologists often moved their practices in search of a greater demand for their services. ${ }^{16}$ Rural towns with a vast territory would have greater difficulty in supporting a gynecologist because people in the outskirts had easier access to gynecologists in adjacent towns. The patients' mobility could also explain why the proportion of women living in towns without a gynecologist in our study was lower than that in the census.

In our study, women in towns without a gynecologist had fewer ambulatory visits for gynecological diagnoses and fewer visits to gynecological clinics than those women in towns with a gynecologist. There were several possibilities for this. First, the rural residents might have actually had better health conditions ${ }^{17}$ or a better self-reported health

Table 3 Distribution of gynecological diseases in adult women in 2010, stratified by age group and residency type (living in towns with a gynecologist or without a gynecologist)

\begin{tabular}{|c|c|c|c|c|c|c|c|c|}
\hline \multirow[t]{3}{*}{ Disease group } & \multicolumn{2}{|l|}{$18-29$ years } & \multicolumn{2}{|l|}{$30-44$ years } & \multicolumn{2}{|l|}{$45-64$ years } & \multicolumn{2}{|l|}{$\geq 65$ years } \\
\hline & G (\%) & NG (\%) & G (\%) & NG (\%) & G (\%) & NG (\%) & G (\%) & NG (\%) \\
\hline & $n=86,529$ & $n=2,962$ & $n=|| 2,83 \mid$ & $n=4,993$ & $n=114,157$ & $n=7,913$ & $n=46,856$ & $n=5,926$ \\
\hline Lower genital tract infections $s^{\mathrm{a}, \mathrm{b}, \mathrm{c}, \mathrm{d}}$ & $3,902(4.5)$ & $109(3.7)$ & $5,558(4.9)$ & $193(3.9)$ & $3,013(2.6)$ & $166(2.1)$ & $347(0.7)$ & $29(0.5)$ \\
\hline Infertility ${ }^{b}$ & $961(1.1)$ & $23(0.8)$ & $2,033(1.8)$ & $36(0.7)$ & $60(0.1)$ & $4(0.1)$ & $2(0.0)$ & $0(0.0)$ \\
\hline Genital dysplasia ${ }^{a, b, c}$ & $4,008(4.6)$ & $10 \mid(3.4)$ & $7,385(6.5)$ & $255(5.1)$ & $4,610(4.0)$ & $235(3.0)$ & $447(1.0)$ & $47(0.8)$ \\
\hline Menopausal disorders ${ }^{c, d}$ & $127(0.1)$ & $3(0.1)$ & $1,198(1.1)$ & $53(1.1)$ & 12,967 (11.4) & $688(8.7)$ & $2,292(4.9)$ & $182(3.1)$ \\
\hline Menstrual disorders and hormonal dysfunction ${ }^{\mathrm{a}, \mathrm{b}, \mathrm{c}, \mathrm{d}}$ & $25,477(29.4)$ & $660(22.3)$ & $28,423(25.2)$ & $882(17.7)$ & $9,084(8.0)$ & $408(5.2)$ & $155(0.3)$ & $7(0.1)$ \\
\hline Endometriosis and pelvic pain ${ }^{a, b, c}$ & $6,784(7.8)$ & $191(6.4)$ & $7,882(7.0)$ & $255(5.1)$ & $2,850(2.5)$ & $155(2.0)$ & $379(0.8)$ & $38(0.6)$ \\
\hline Reproductive tract malignancy & $84(0.1)$ & $5(0.2)$ & $437(0.4)$ & $16(0.3)$ & $\mathrm{I}, \mathrm{II}(\mathrm{I}(\mathrm{I.0})$ & $77(1.0)$ & $459(1.0)$ & $46(0.8)$ \\
\hline Inflammatory disease of the upper genital tract ${ }^{\mathrm{a}, \mathrm{b}, \mathrm{c}, \mathrm{d}}$ & $17,943(20.7)$ & $453(15.3)$ & $28,802(25.5)$ & $1,019(20.4)$ & $18,574(16.3)$ & I,002 (12.7) & $2,444(5.2)$ & $227(3.8)$ \\
\hline Benign disorders of the uterus and ovaries ${ }^{\mathrm{a}, \mathrm{b}, \mathrm{c}, \mathrm{d}}$ & $3,711(4.3)$ & $84(2.8)$ & $10,534(9.3)$ & $366(7.3)$ & $7,927(6.9)$ & $365(4.6)$ & $337(0.7)$ & $23(0.4)$ \\
\hline Other disorders of female genital organs ${ }^{c, d}$ & $446(0.5)$ & $14(0.5)$ & $783(0.7)$ & $25(0.5)$ & $429(0.4)$ & II (0.I) & $75(0.2)$ & $2(0.0)$ \\
\hline Gynecological examination ${ }^{b, c, d}$ & $749(0.9)$ & $29(1.0)$ & $1,395(1.2)$ & $34(0.7)$ & $909(0.8)$ & $42(0.5)$ & $170(0.4)$ & II (0.2) \\
\hline Encounter for contraceptive management & $130(0.2)$ & $3(0.1)$ & $303(0.3)$ & II (0.2) & $86(0.1)$ & $3(0.0)$ & $\mathrm{I}(0.0)$ & $0(0.0)$ \\
\hline
\end{tabular}

Notes: aSignificant difference between women living in towns with and without a gynecologist in women aged 18-29 years; $P<0.05$. bSignificant difference between women living in towns with and without a gynecologist in women aged 30-44 years; $P<0.05$. 'Significant difference between women living in towns with and without a gynecologist in women aged 45-64 years; $P<0.05$. 'Significant difference between women living in towns with and without a gynecologist in women aged 65 years and over; $P<0.05$.

Abbreviations: $\mathrm{G}$, gynecologist; NG, no gynecologist; $n$, number. 
Table 4 Number and percentage of women living in towns without a gynecologist and having gynecological diseases in 2010 ( $n=5,189$ ), stratified by disease group and type of consulted clinic

\begin{tabular}{|c|c|c|c|c|}
\hline Disease group & $\begin{array}{l}\text { Nongynecologist } \\
\text { in town, } \mathbf{n}(\%)\end{array}$ & $\begin{array}{l}\text { Gynecologist } \\
\text { out of town, n (\%) }\end{array}$ & $\begin{array}{l}\text { Nongynecologist } \\
\text { out of town, n (\%) }\end{array}$ & $\begin{array}{l}\text { Total*, } \\
\text { n }\end{array}$ \\
\hline Lower genital tract infections & $35(7.0)$ & $436(87.7)$ & $31(6.2)$ & 497 \\
\hline Infertility & I (I.6) & $62(98.4)$ & $3(4.8)$ & 63 \\
\hline Genital dysplasia & $115(18.0)$ & $475(74.5)$ & $71(11.1)$ & 638 \\
\hline Menopausal disorders & $267(28.8)$ & $581(62.7)$ & $157(17.0)$ & 926 \\
\hline Menstrual disorders and hormonal dysfunction & $401(20.5)$ & $\mathrm{I}, 546(79.0)$ & $256(13.1)$ & 1,957 \\
\hline Endometriosis and pelvic pain & $183(28.6)$ & $351(54.9)$ & $156(24.4)$ & 639 \\
\hline Reproductive tract malignancy & $8(5.6)$ & $121(84.0)$ & $63(43.8)$ & 144 \\
\hline Inflammatory disease of the upper genital tract & $354(13.1)$ & $2,371(87.8)$ & $12 \mid(4.5)$ & 2,701 \\
\hline Benign disorders of the uterus and ovaries & $21(2.5)$ & $811(96.8)$ & $32(3.8)$ & 838 \\
\hline Other disorders of female genital organs & $4(7.7)$ & $45(86.5)$ & $4(7.7)$ & 52 \\
\hline Gynecological examination & $0(0.0)$ & I I 3 (97.4) & $4(3.4)$ & 116 \\
\hline Encounter for contraceptive management & $0(0.0)$ & $17(100.0)$ & $0(0.0)$ & 17 \\
\hline Total* & $1,209(23.3)$ & $4,074(78.5)$ & $773(14.9)$ & 5,189 \\
\hline
\end{tabular}

Notes: *One woman may have more than one diagnosis. The total number of women did not represent the total number of diagnoses.

Abbreviation: $n$, number.

status. ${ }^{18,19}$ Their perceived general health conditions might make them less inclined to visit a doctor or receive preventive health examinations, ${ }^{20}$ and it may lead to under-reporting in rural areas. ${ }^{21}$ Second, gynecological diseases might be underdiagnosed in towns without a gynecologist because nongynecologist physicians are less trained in gynecology. ${ }^{22}$ Third, less accessibility to and availability of gynecologists for women in towns without a gynecologist might act as a barrier to seeking medical help for gynecological diseases.

Among all adult women in our study, women aged 65 years or older had the lowest rates of gynecological diseases and visits to a gynecologist, while women of childbearing age had the highest rates. A similar pattern existed in other countries, as well. ${ }^{12,23}$ Another study in Taiwan also revealed that elderly people usually utilize more medical services than other age groups. ${ }^{24}$ Obviously, menopause played a major role in the transition of health care needs in women. Therefore, the age structure of inhabitants in a town should be taken into consideration in health policy planning.

In our study, the menstrual disorders and hormonal dysfunction disease group was the most common gynecological disease in women aged 18-29 years, and menopausal disorder increased rapidly in middle-aged and elderly women. The results were consistent with the dynamic hormonal changes in women's physiology. On the other hand, the prevalence of reproductive tract malignancy was low and did not reveal significant differences between women in towns with and without a gynecologist. However, the data of cancer staging were not available in the NHIRD datasets, and we could not know directly whether the availability of gynecologists delayed the diagnosis of malignancies and influenced the outcome of treatment.
Some studies in the US revealed that gynecologists provide the majority of services for gynecological diseases. ${ }^{23,25}$ Our study had similar findings. Especially with respect to infertility, benign disorders of the uterus and ovaries, gynecological examinations, and contraceptive problems, most women in towns without a gynecologist visited gynecologists out of town. Perhaps the management of these disorders required more skillful practitioners, and gynecologists were preferred to provide these services. ${ }^{26}$ In contrast, for menopausal disorders, endometriosis and pelvic pain, and menstrual disorders and hormonal dysfunction, over one-fifth of the women in towns without a gynecologist received care locally. This implied that nongynecologists might handle some common minor gynecological diseases fairly well.

For women in towns without a gynecologist, the demand for the services of gynecologists might be partially met by mobile gynecological clinics under contract, ${ }^{27}$ free transportation to gynecological clinics, or compensation for traveling expenses. Other fundamental solutions include enhancing the gynecological skills and knowledge of family physicians through training programs or continuing education, and by providing an effective referral network.

\section{Limitations}

There were some limitations in our current study. First, with our algorithm, the residency could not be identified in $6.3 \%$ of women because they did not utilize any ambulatory medical services during the year. Perhaps their unmet needs in gynecological services also deserved investigation. Second, the diagnosis codes from deidentified claims data are limited in that we only could access to determine their accuracy. Furthermore, disease severity and urgency were 
not specified in the claims; neither were the outcomes and disposition by physicians. Fourth, there may be misclassifications of residency if women routinely chose medical care outside of their towns of residence. However, this might not be of great concern in health policy planning because it means that these women could at least receive gynecological care in much the same way that urban inhabitants do. Finally, the NHIRD claims did not include the beneficiaries' information regarding their economic status, education level, and health status, nor did they provide information regarding other factors that might influence help-seeking behaviors.

\section{Conclusion}

The shortage of gynecologists in many towns, as well as the disparity of gynecological care between towns with and without a gynecologist, exists in Taiwan. The deteriorating situation in recruiting medical graduates into obstetrics and gynecology might widen the rural-urban disparity in the near future. The consequences of undersupplied gynecological care deserve further investigation.

\section{Acknowledgments}

This study is based in part on data from the NHIRD provided by the Bureau of National Health Insurance, Department of Health, and managed by the National Health Research Institutes. The interpretation and conclusions contained herein do not represent those of the Bureau of National Health Insurance, Department of Health, or National Health Research Institutes.

\section{Disclosure}

The authors report no conflicts of interest in this work.

\section{References}

1. Ozgediz D, Galukande M, Mabweijano J, et al. The neglect of the global surgical workforce: experience and evidence from Uganda. World $J$ Surg. 2008;32(6):1208-1215.

2. The Society of Obstetricians and Gynaecologists of Canada. A National Birthing Initiative for Canada: An Inclusive, Integrated and Comprehensive Pan-Canadian Framework for Sustainable Family-Centered Maternity and Newborn Care. Ottawa, ON: The Society of Obstetricians and Gynaecologists of Canada; 2008. Available from: http://sogc.org/ wp-content/uploads/2012/09/BirthingStrategyVersioncJan2008.pdf. Accessed July 18, 2014.

3. Fukuda Y, Harada T. Gender differences in specialty preference and mismatch with real needs in Japanese medical students. BMC Med Educ. 2010;10:15.

4. Satiani B, Williams T, Landon M, Ellison C, Gabbe S. A critical deficit of OBYGN surgeons in the US by 2030. Surgical Science. 2011;2(2):95-101.

5. Anderson BL, Hale RW, Salsberg E, Schulkin J. Outlook for the future of the obstetrician-gynecologist workforce. Am J Obstet Gynecol. 2008;199(1):88.e1-e8.
6. Ide H, Yasunaga H, Kodama T, Koike S, Taketani Y, Imamura T. The dynamics of obstetricians and gynecologists in Japan: a retrospective cohort model using the nationwide survey of physicians data. J Obstet Gynaecol Res. 2009;35(4):761-766.

7. Wang PH, Sheu BC, Yeh JY. The Sunset Industry: obstetrics and gynecology concerns about the shortage of obstetricians and gynecologists. Am J Obstet Gynecol. 2009;201(4):e12.

8. Directorate-General of Budget, Accounting and Statistics, Executive Yuan, R.O.C. (Taiwan) [webpage on the Internet]. Ministry of the Interior in Taiwan: Gross domestic product. Available from: http://eng.dgbas.gov. tw/mp.asp?mp=2. Accessed February 17, 2015.

9. Taiwan Medical Association [webpage on the Internet]. Statistics yearbook of practicing physicians and health care organizations in Taiwan; 2013. Available from: http://www.tma.tw. Accessed February16, 2014.

10. National Health Insurance Research Database [webpage on the Internet]. Taipei: National Health Insurance Research Database. National Health Research Institutes; 2003. Available from: http://w3.nhri.org.tw/nhird. Accessed February 16, 2012.

11. ICD9.chrisendres.com [homepage on the Internet]. International Classification of Diseases, Ninth Revision, Clinical Modification. Available from http://icd9cm.chrisendres.com/. Accessed February 17, 2015.

12. Nicholson WK, Ellison SA, Grason H, Powe NR. Patterns of ambulatory care use for gynecologic conditions: A national study. Am JObstet Gynecol. 2001;184(4):523-530.

13. perl.org [homepage on the Internet]. The Perl Programming Language. Available from: http://www.perl.org/. Accessed February 17, 2015.

14. Hicks LL, Glenn JK. Rural populations and rural physicians: estimates of critical mass ratios, by specialty. J Rural Health. 1991;7 (4 Suppl):357-372.

15. Baumgardner JR. Physicians' services and the division of labor across local markets. J Polit Econ. 1988;96(5):948-982.

16. Ricketts TC, Tropman SE, Slifkin RT, Konrad TR. Migration of obstetrician-gynecologists into and out of rural areas, 1985-1990. Med Care. 1996;34(5):428-438.

17. O'Reilly G, O'Reilly D, Rosato M, Connolly S. Urban and rural variations in morbidity and mortality in Northern Ireland. BMC Public Health. 2007;7:123.

18. Maas J, Verheij RA, Groenewegen PP, de Vries S, Spreeuwenberg P. Green space, urbanity, and health: how strong is the relation? J Epidemiol Community Health. 2006;60(7):587-592.

19. Verheij RA, Maas J, Groenewegen PP. Urban-rural health differences and the availability of green space. Eur Urban Reg Stud. 2008;15(4): 307-316.

20. Larson S, Correa-de-Araujo R. Preventive health examinations: a comparison along the rural-urban continuum. Womens Health Issues. 2006;16(2):80-88.

21. Kroneman M, Verheij R, Tacken M, van der Zee J. Urban-rural health differences: primary care data and self reported data render different results. Health Place. 2010;16(5):893-902.

22. Quibel A, Puscasiu L, Marpeau L, Roman H. General practitioners and the challenge of endometriosis screening and care: results of a survey. Gynecol Obstet Fertil. 2013;41(6):372-380.

23. Scholle SH, Chang JC, Harman J, McNeil M. Trends in women's health services by type of physician seen: data from the 1985 and 1997-1998 NAMCS. Womens Health Issues. 2002;12(4):165-177.

24. Chen TJ, Chou LF, Hwang SJ. Patterns of ambulatory care utilization in Taiwan. BMC Health Serv Res. 2006;6:54.

25. Bartman BA, Weiss KB. Women's primary care in the United States: a study of practice variation among physician specialties. Journal of Women's Health. 1993;2(3):261-268.

26. Schmittdiel J, Selby JV, Grumbach K, Quesenberry CP. Women's provider preferences for basic gynecology care in a large health maintenance organization. J Womens Health Gend Based Med. 1999;8(6):825-833.

27. Cameron K, Hansen E. Health planning for immigrants. Health Prog. 2005;86(1):26-29, 60. 
Patient Preference and Adherence

Dovepress

\section{Publish your work in this journal}

Patient Preference and Adherence is an international, peer-reviewed, open access journal that focuses on the growing importance of patient preference and adherence throughout the therapeutic continuum. Patient satisfaction, acceptability, quality of life, compliance, persistence and their role in developing new therapeutic modalities and compounds to optimize

Submit your manuscript here: http://www.dovepress.com/patient-preference-and-adherence-journ clinical outcomes for existing disease states are major areas of interest for the journal. This journal has been accepted for indexing on PubMed Central The manuscript management system is completely online and includes a very quick and fair peer-review system, which is all easy to use. Visit http://www. dovepress.com/testimonials.php to read real quotes from published authors. 